\title{
PRIMARY LUNG SQUAMOUS CELL CARCINOMA IN A LARY BREED COCK (GALLUS GALLUS DOMESTICUS) WITH MULTIPLE SKIN METASTASES
}

\author{
M. HASHEMNIA ${ }^{1} \&$ Z. NIKOUSEFAT ${ }^{2}$ \\ ${ }^{1}$ Department of Pathobiology; ${ }^{2}$ Department of Clinical Sciences; School of \\ Veterinary Medicine, Razi University, Kermanshah, Iran
}

\section{Summary}

Hashemnia, M. \& Z. Nikousefat, 2017. Primary lung squamous cell carcinoma in a Lary breed cock (Gallus gallus domesticus) with multiple skin metastases. Bulg. J. Vet. Med., 20, No 4, 392-399.

The present study describes for the first time a case of primary lung squamous cell carcinoma with multiple skin metastases in a 7-year-old Lary breed cock. On physical examination, multiple, firm, mobile, ulcerative nodules, 3 to $4 \mathrm{~cm}$ in diameter were observed on the neck. Atypical squamous cells were observed in the skin fine needle aspiration. Histopathologically, variably sized masses of concentrically arranged neoplastic squamous epithelial cells with the horn pearl formation were observed in the dermis. At necropsy, the lung was consolidated and had multifocal tan masses containing a tenacious exudate. Similar nodules were observed in the liver. On the histopathological sections, the lung and liver contained large multifocal areas of necrosis intermixed with cords, sheets, and nests of round to oval neoplastic cells. The presence of keratin material was common in the center of neoplastic cells islands as keratin pearls. Given the morphologic features of the neoplasm, a diagnosis of primary lung squamous cell carcinoma was made. Although the incidence of primary lung SCC is likely too low in the birds, but it should be considered in the differential diagnosis.

Key words: cock, lung squamous cell carcinoma, skin metastasis

The avian lung serves as a metastatic site for many neoplasms, including fibrosarcoma, adenocarcinoma, haemangiosarcoma, malignant melanoma, mesothelioma and osteosarcoma. In contrast, primary neoplasms of the avian respiratory system are rare (Latimer, 1994).

Squamous cell carcinoma (SCC) often begins with an area of squamous metapla- sia or dysplasia in the bronchial epithelium that progresses to carcinoma in situ. Grossly, the tumour has an irregular, often friable, grey-white cut surface, commonly showing a large area of central necrosis, with or without cavitation. Histopathologically, SCCs have a significant component or predominance of solid carcinoma containing moderate to large amounts 
of homogenous amphophilic to eosinophilic cytoplasm and round to oval, centrally placed nuclei (Husain \& Kumar, 2005).

While evidences of keratinisation and intercellular bridges are constant findings in well-differentiated squamous cell neoplasm, poorly differentiated tumours have only minimal residual squamous cell features. Well-differentiated SCCs tend to spread locally within the thoracic cavity, directly involving adjacent mediastinal structures. Poorly differentiated carcinoma tends to metastasise early and to distant sites (Wilson \& Dungworth, 2002; Noguchi \& Shimosato, 2010).

The most common sites of metastasis of lung tumours include the bones, liver, adrenal gland and brain, while the skin is rarely affected and is an indicator of bad prognosis. In humans, like animals, the incidence of cutaneous metastases in lung cancer is considered low with the majority of studies conducted in recent years demonstrating incidences between $1.7 \%$ to $3.1 \%$. In the majority of studies on skin metastases from lung cancer, the histological type most frequently disseminated to the skin is adenocarcinoma. However, in Brownstein \& Helwig's study, squamous carcinoma was as prevalent as adenocarcinoma (Brownstein \& Helwig, 1972; Marcoval et al., 2011).

To date, there is no report about spontaneous primary pulmonary SCC in birds. The present report describes a case of primary SCC of the lung, confirmed by cytology and histopathology that metastasised to the liver and skin in a 7 year-old cock.

A 7-year-old Lary breed cock (Gallus gallus domesticus) was presented to the Veterinary Teaching Hospital, Razi University, with four-month history of dyspnea and tachypnea and presence of multiple exophytic skin lesions, progressively increasing in size over his neck. Physical examination revealed multiple, firm, mobile, ulcerative nodules, 3 to $4 \mathrm{~cm}$ in diameter with hyperaemic centers and elevated rolled edges on the neck (Fig. 1).

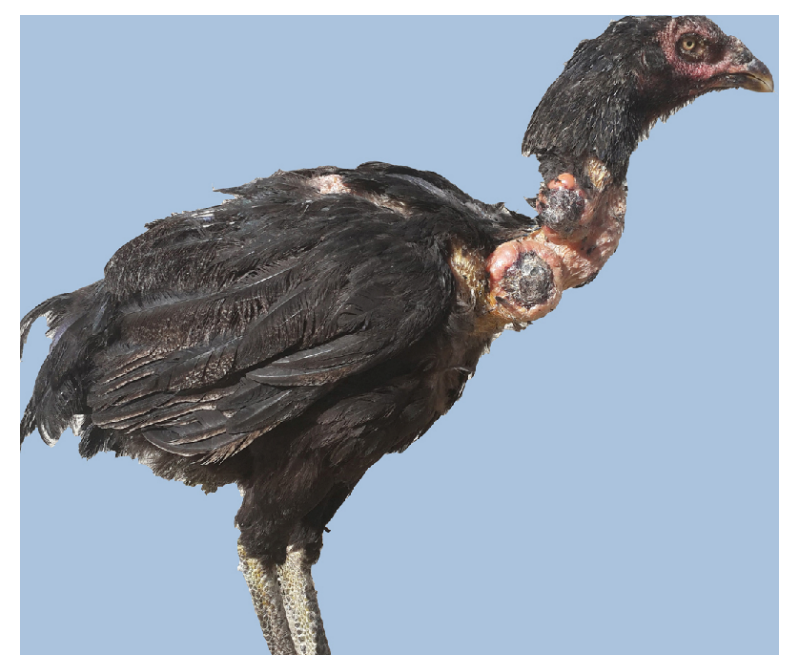

Fig. 1. Appearance of the cock at initial examination. Firm, mobile, ulcerative nodules, 3 to $4 \mathrm{~cm}$ in diameter with hyperaemic centers and elevated rolled edges observe on the distal part of the neck. 


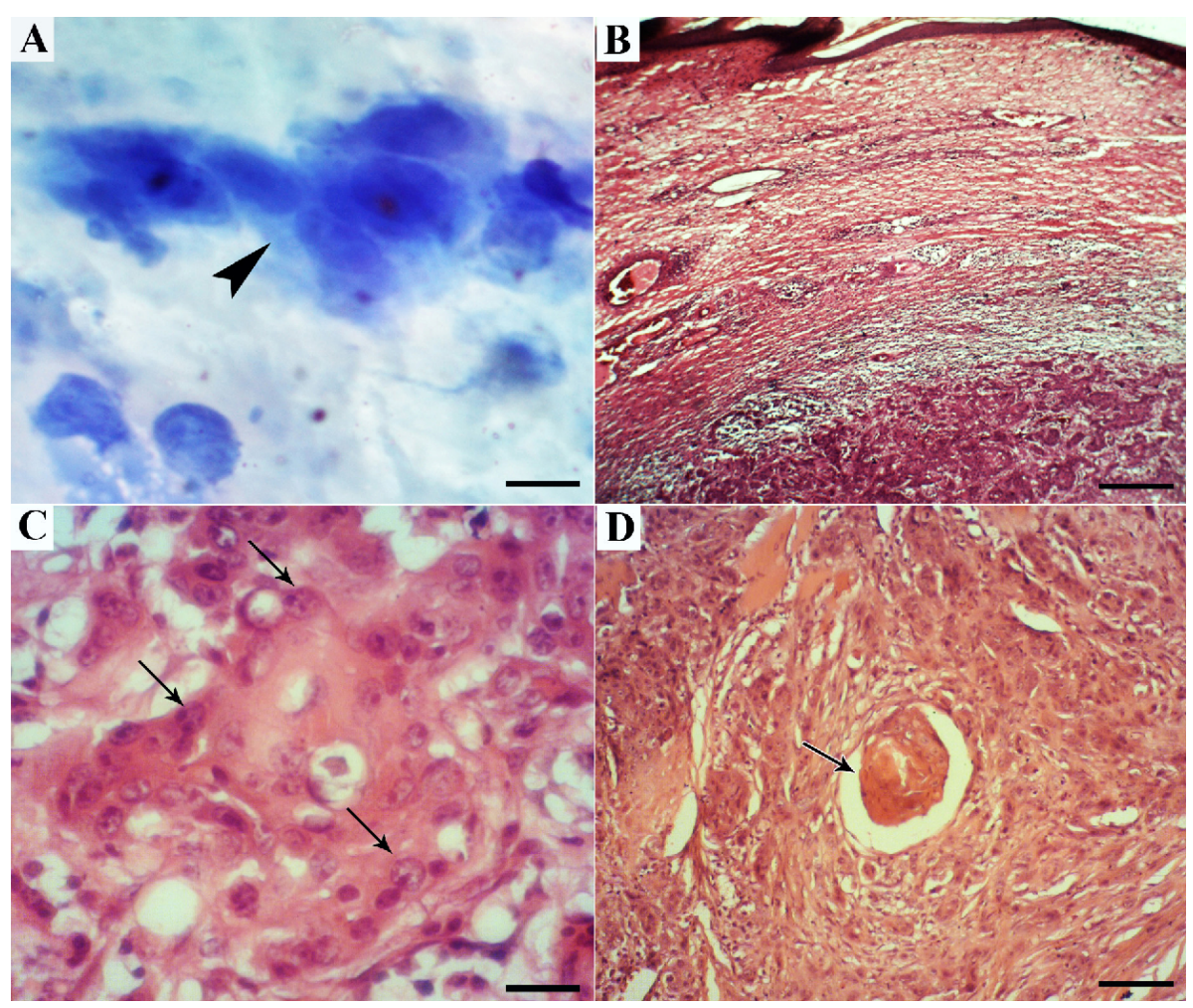

Fig. 2. A) Skin FNA cytology. Nest of atypical squamous cells (arrow head) (MGG staining; $\mathrm{Bar}=5 \mu \mathrm{m}$ ); B) Irregular masses and cords of neoplastic epithelial cells invading the dermis (H\&E; Bar=100 $\mu \mathrm{m})$; C) Neoplastic epithelial cells with large, ovoid, often vesicular nuclei with 1 or 2 prominent nucleolus, abundant eosinophilic cytoplasm and distinct cell borders (arrows) (H\&E; Bar $=10 \mu \mathrm{m})$; D) Large mass of concentrically arranged squamous epithelial cells with "horn pearl" formation (arrow) (H\&E; Bar=40 $\mu \mathrm{m})$.

The appearance of these projections was compatible with cutaneous horn.

A fine needle aspiration (FNA) from skin lesions was done and stained with May Grunwald Giemsa (MGG). Additionally, multiple skin biopsies were taken and they were fixed in $10 \%$ neutral buffered formalin, processed routinely, embedded in paraffin, sectioned at $5 \mu \mathrm{m}$ thickness, stained with haematoxylin and eosin (H\&E) according to the standard histopathological methods.

Atypical squamous cells were diagnosed in the skin FNA cytology (Fig. 2A).
In the histopathologic examination, the neoplastic epithelial cells were observed in the dermis as islands and cords arranged without an association to the overlying epidermis (Fig. 2B). Individual tumour cells had large, ovoid, often vesicular nuclei with 1 or 2 prominent nucleoli, abundant eosinophilic cytoplasm and distinct cell borders (Fig. 2C). The variable amount of keratin was seen as a distinct keratin pearl formation and also intracytoplasmic, eosinophilic fibrillar material into the neoplastic cells (Fig. 2D). Ulceration was accompanied by an infiltrate of 
heterophils into the superficial part of the tumour, while plasma cells and lymphocytes are found in the deeper parts of the tumour. These features were compatible with metastatic squamous cell carcinoma.

The bird was euthanised a month later due to severe dyspnea. In postmortem examination, both lungs were consolidated and had multifocal tan masses. On cut section, the masses were firm, had areas of necrosis and haemorrhage and often contained a tenacious exudate. Simi- lar nodules were observed in the liver (Fig. 3)

On the histopathological sections, the lung contained large multifocal areas of necrosis intermixed with cords, sheets, and nests of round to oval neoplastic cells (Fig. 4). These cells had large vesicular round to oval nuclei with 1 or 2 prominent nucleoli and abundant eosinophilic cytoplasm. The presence of keratin material was common in the center of neoplastic cells islands as keratin pearls (Fig. 5A).

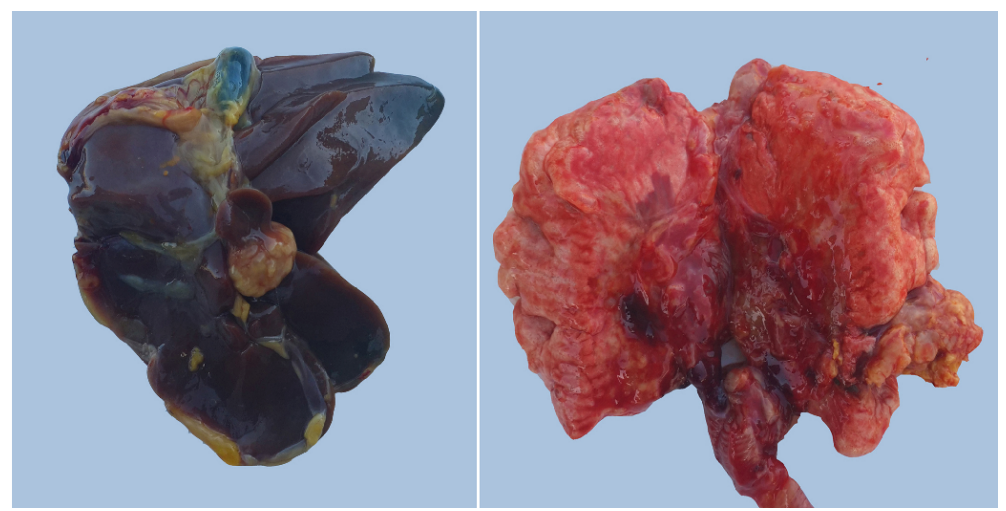

Fig. 3. Lung and liver with multifocal, raised, tan-colored masses

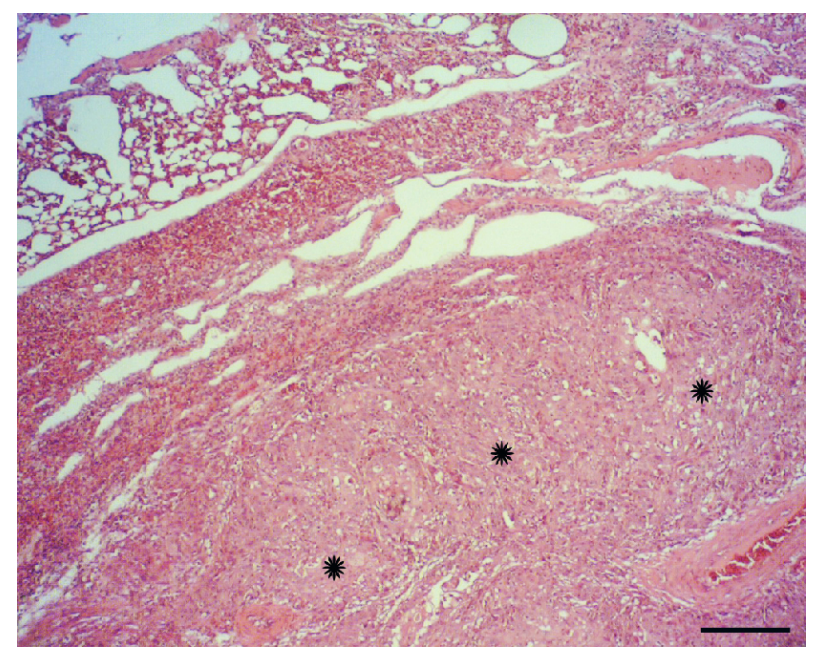

Fig. 4. Lung; cock. Large multifocal areas of necrosis intermixed with cords, sheets, and nests of round to oval neoplastic cells (stars) $(\mathrm{H} \& \mathrm{E} ; \mathrm{Bar}=100 \mu \mathrm{m})$. 


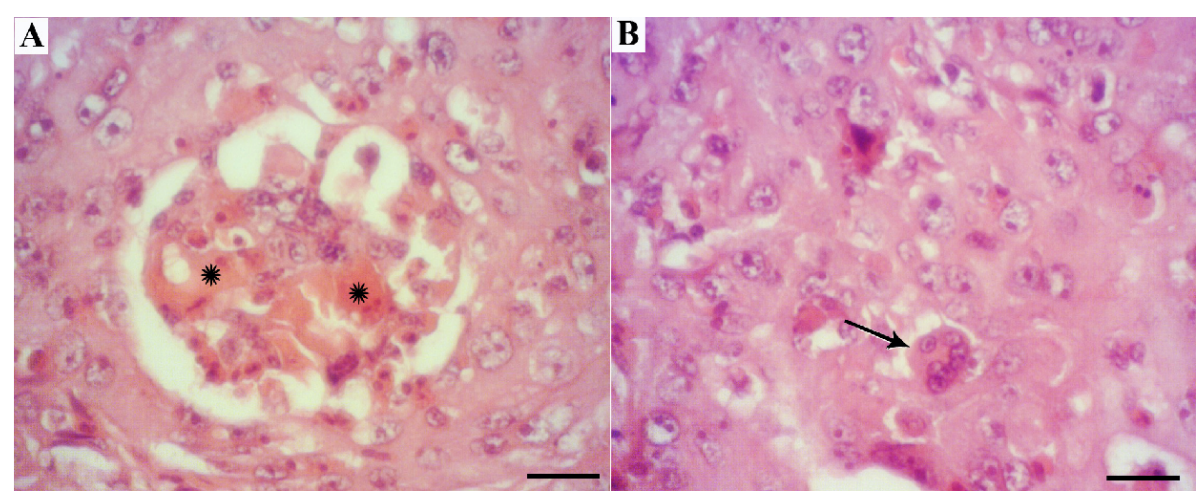

Fig. 5. A) Keratin pearl surrounded by neoplastic epithelial cells (stars) (H\&E; Bar=10 $\mu \mathrm{m})$; B) Multinucleated giant cell among the neoplastic cells (arrow) $(\mathrm{H} \& \mathrm{E} ; \mathrm{Bar}=10 \mu \mathrm{m})$.

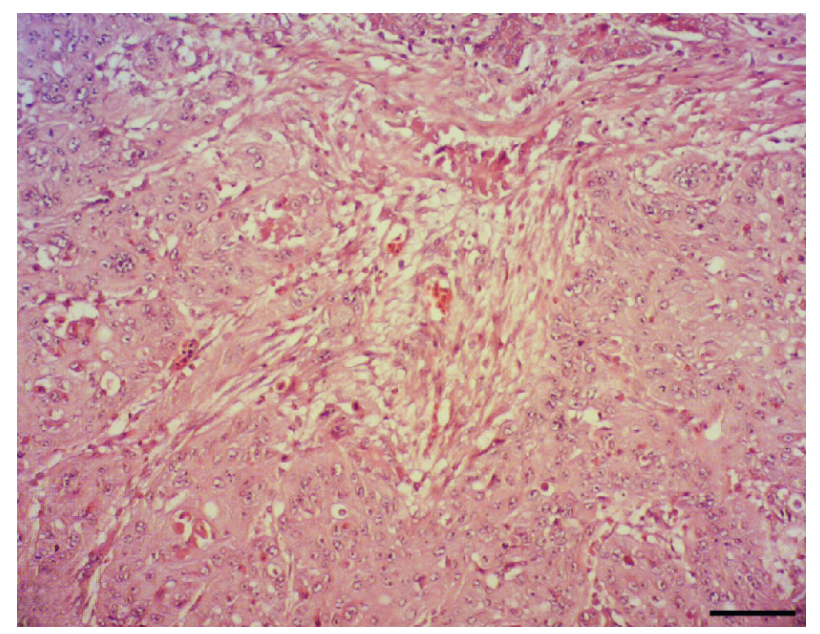

Fig. 6. Sheets of round to oval neoplastic cells with vesicular nuclei and abundant eosinophilic cytoplasm surrounding a central area of necrosis (H\&E; Bar=40 $\mu \mathrm{m})$.

Unusual multinucleated giant cells were often observed (Fig. 5B).

Histologically, the liver had multifocal areas of proliferation of round to oval neoplastic cells surrounding a central area of necrosis. The neoplastic cells were arranged in sheets and nests and often had vesicular nuclei with 1 or 2 prominent nucleoli and abundant eosinophilic cytoplasm. Keratin pearls were common in the sections (Fig. 6).
This study was approved by the State Committee on Animal Ethics, Razi University, Kermanshah, Iran. In addition, recommendations of European Council Directive $(86 / 609 /$ EC) of November 24 , 1986, regarding the protection of animals used for experimental purposes were considered.

Primary lung tumours and their metastasis to the other tissues and organs are rare in birds. This study is the first report 
of lung SSC and its metastasis to the skin in a bird.

The main clinical signs associated with lung tumours include dyspnea, coughing, haemoptysis, lethargy, anorexia, weight loss (Jean et al., 2011). The cock in the present case report showed signs of dyspnea, tachypnea and lethargy, but anorexia and weight loss were not observed despite the aggressive and advanced stage of disease.

Although the appearance of the skin lesions in preliminary physical examination in this case wass similar to the cutaneous horn, the lesions were diagnosed as SCC in the histopathologic examination.

The cutaneous horn is clinically presented as a conical dense hyperkeratotic projection of skin that can appear in any part of the body and is histologically composed of concentric layers of keratinised epithelial cells. Keratosis, sebaceous molluscum, verruca, trichilemma, Bowen's disease, squamous cell carcinoma, malignant melanoma, and basal cell carcinoma have all been described in association with cutaneous horns, highlighting the importance of histopathological examination to rule out malignancy because clinical features cannot assure a correct diagnosis (Copcu et al., 2004; Kumaresan et al., 2008; Mantese et al., 2010; Augusto Gomes et al., 2011).

SCC in mammals is often associated with proliferation of surface keratinocytes following radiation (usually ultraviolet) or exposure to organic hydrocarbons and related compounds. Papilloma virus infection, trauma and chronic inflammation are also associated or etiologic factors. These tumours are usually locally invasive and slow to metastasise (Hafner et al., 1993).

Neoplasms in avian species may arise from embryonic rests, may be induced by a virus or by intrinsic genetic or hormonal influences, or may be associated with extrinsic environmental factors. Although some researchers described squamous cell carcinomas in two young chickens experimentally infected with the $\mathrm{MH} 2$ and MC29 strains of avian oncomavirus. In another experimental study, SCC lesions were experimentally induced in chickens latently infected with fowl pox following application of methylcholanthrene (Hafner et al., 1993).

In the present case, the tumour showed no connection with the epithelium and was located in the deep dermis. Hence, its features were compatible with metastatic squamous cell carcinoma, not primary skin SCC.

Generally, metastatic SCC should be distinguished from primary squamous cell carcinoma of skin. Usually metastatic deposits are located in the deeper dermis and subcutaneous tissues, sparing the superficial cutis (Sharma et al., 2009; Bansal et al., 2010).

SCC may show a progressive disease pattern, ranging from mild dysplasia (atypia) to carcinoma in situ to invasive squamous cell carcinoma. Traditionally, squamous cell carcinomas have been classified as well-, moderately, or poorly differentiated. Most of the factors influencing this classification involve the presence of either keratinisation or intercellular bridges. As in our case, moderately differentiated tumours may still show areas in which either keratinisation or intercellular bridges can be identified. However, more extensive areas of haemorrhage and necrosis, which may obscure the true nature of the neoplasm, may also be observed (Moran \& Suster, 2010).

Recently, a case of primary lung SCC has been reported in a 3-year-old male rhesus macaque with metastasis to the kidneys and liver. However, skin metas- 
Primary lung squamous cell carcinoma in a Lary breed cock (Gallus gallus domesticus) with ...

tasis were not observed in this animal, but some histopathological findings such as the presence of large multifocal areas of necrosis intermixed with cords, sheets, and nests of round to oval neoplastic cells and also multinucleated giant cells are similar to our case (Jean et al., 2011). Other lesions in this case which were absent in the cock were moderate to severe infiltration of neutrophils and haemosiderin-laden macrophages in the pulmonary parenchyma and the presence of large numbers of neutrophils in the bronchi (Jean et al., 2011).

In humans, the major risk factor in the development of lung SCC is cigarette smoking (Junker et al., 2000; Sakurai et $a l .$, 2004). In addition, exposure to asbestos, polycyclic aromatic hydrocarbons, arsenic, chromium compounds and radiation are other predisposing factors. Furthermore, vitamin A and folate deficiencies contribute to the development of multifocal squamous metaplasia, which in turn can predispose tissue to becoming neoplastic (Maggiore et al., 2004). There is no information about the environment and nutritional conditions of the cock in the current case report; so it is very difficult to identify the tumour-causing agents.

In conclusion, skin metastases from internal malignancies are rare and may have an unpredictable presentation such as a cutaneous horn like lesions in the present case. Although the incidence of primary lung SCC is likely too low to elucidate its primary risk factors and prognosis in the birds, the techniques used for diagnosis appear to be consistent with those used in other species.

\section{ACKNOWLEDGMENTS}

We thank the authorities of Veterinary School, Razi University for their cooperation.

\section{REFERENCES}

Augusto Gomes, C., M. C. M. N. Castanon, C. Couto Gomes \& P. M. Campanha, 2011. Giant cutaneous horn in Afro-Brazilian descendent patient: Case report and literature review. Journal of Clinical \& Experimental Dermatology, 2, 137-137.

Bansal, R., T. Patel, J. Sarin, B. Parikh, A. Ohri \& P. Trivedi, 2010. Cutaneous and subcutaneous metastases from internal malignancies: An analysis of cases diagnosed by fine needle aspiration. Diagnostic $C y$ topathology 39, 882-887.

Brownstein, M.H. \& E.B. Helwig, 1972. Metastatic tumours of the skin. Cancer, 29 , 1298-1307.

Copcu, E., N. Sivrioglu \& N. Culhaci, 2004. Cutaneous horns: Are these lesions as innocent as they seem to be? World Journal of Surgical Oncology, 2, 18-22.

Jean, S.M., P.R. Morales, K. Paul \& A.P. Garcia, 2011. Spontaneous primary squamous cell carcinoma of the lung in a Rhesus macaque (Macaca mulatta). Journal of the American Association for Laboratory Animal Science, 50, 404-408.

Junker, K., T. Wiethege \& K. M. Muller, 2000. Pathology of small-cell lung cancer. Journal of Cancer Research and Clinical Oncology, 126, 361-368.

Hafner, S., B. G. Harmon, R. G. Stewart \& G. N. Rowland, 1993. Avian keratoacanthoma (dermal squamous cell carcinoma) in broiler chicken carcasses. Veterinary Pathology, 30, 265-270.

Husain, A. \& V. Kumar, 2005. The lung. In: Pathologic Basis of Disease, $7^{\text {th }}$ edn, ed C. Robbins, Saunders, Philadelphia, pp. 711772.

Kumaresan, M., P. Kumar \& M. V. Pai, 2008. Giant cutaneous horn. Indian Journal of Dermatology, 53, 199-200.

Latimer, K. S., 1994. Oncology. In: Avian Medicine: Principles and Application, eds $\mathrm{B}$. W. Ritchie, G. J. Harrison, L. R. Harrison, Wingers Publishing Inc, Lake Worth, pp. 645-646. 
Maggiore, C., A. Mule, G. Fadda, E. D. Rossi, L. Lauriola, F. M. Vecchio, A. Capelli, 2004. Histological classification of lung cancer. Rays, 29, 353-355.

Mantese, S. A. O., P. M. Diogo, A. Rocha, A L. C. V. Berbert, A. K. M. Ferreira \& T. C. Ferreira, 2010. Cutaneous horn: A retrospective histopathological study of 222 cases. Brazilian Annals of Dermatology, 85, 157-163.

Marcoval, J., R. María Penín, R. Llatjós \& I. Martínez-Ballarín, 2011. Cutaneous metastasis from lung cancer: Retrospective analysis of 30 patients. Australasian Journal of Dermatology, 53, 288-290.

Moran, C. A. \& S. Suster, 2010. Tumors and Tumor-like Conditions of the Lung and Pleura, $1^{\text {st }}$ edn. Saunders Elsevier, Philadelphia, PA, pp. 52-55.

Noguchi, M. \& Y. Shimosato, 2010. Pulmonary neoplasms. In: Sternberg's Diagnostic Surgical Pathology, $5^{\text {th }}$ edn. Philadelphia: Lippincott Williams and Wilkins, pp. 1054-1095.

Sakurai, H., H. Asamura, S. Watanabe, K. Suzuki \& R. Tsuchiya, 2004. Clinicopathologic features of peripheral squamous cell carcinoma of the lung. The Annals of Thoracic Surgery, 78, 222-227.

Sharma, S., M. Kotru, A. Yadav, M. Chugh, A. Chawla \& M. Makhija, 2009. Role of fine-needle aspiration cytology in evaluation of cutaneous metastases. Diagnostic Cytopathology, 37, 876-880.

Wilson, D. W. \& D. L. Dungworth, 2002. Tumors of the respiratory tract. In: Tumors in Domestic Animals, $4^{\text {th }}$ edn, ed. D. J. Moulten, Blackwell Publishing Company, Ames, IA, pp. 365-400.

Paper received 02.01.2016; accepted for publication 26.02.2016

\section{Correspondence:}

M. Hashemnia Department of Pathology, School of Veterinary Medicine, Razi University, P.O. Box: 67156-85414, Kermanshah, Iran phone: +98-83-38322599-38329540 email: m.hashemnia@razi.ac.ir 